\title{
Patterns of Regional Brain Hypometabolism Associated with Knowledge of Semantic Features and Categories in Alzheimer's Disease
}

\author{
Roland Zahn ${ }^{1,2}$, Peter Garrard ${ }^{3,4}$, Jochen Talazko' ${ }^{1}$, Matthias Gondan ${ }^{5}$, \\ Philine Bubrowski ${ }^{1}$, Freimut Juengling ${ }^{6}$, Helen Slawik ${ }^{1}$, \\ Petra Dykierek ${ }^{1}$, Bernd Koester ${ }^{1}$, and Michael Hull ${ }^{1}$
}

\begin{abstract}
The study of semantic memory in patients with Alzheimer's disease $(\mathrm{AD})$ has raised important questions about the representation of conceptual knowledge in the human brain. It is still unknown whether semantic memory impairments are caused by localized damage to specialized regions or by diffuse damage to distributed representations within nonspecialized brain areas. To our knowledge, there have been no direct correlations of neuroimaging of in vivo brain function in $\mathrm{AD}$ with performance on tasks differentially addressing visual and functional knowledge of living and nonliving concepts. We used a semantic verification task and resting 18-fluorodeoxyglucose positron emission tomography in a group of mild to moderate $\mathrm{AD}$ patients to investigate this issue. The four task conditions required semantic knowledge of (1) visual, (2) functional properties of living objects, and (3) visual or (4) functional
\end{abstract}

properties of nonliving objects. Visual property verification of living objects was significantly correlated with left posterior fusiform gyrus metabolism (Brodmann's area [BA] 37/19). Effects of visual and functional property verification for nonliving objects largely overlapped in the left anterior temporal (BA 38/20) and bilateral premotor areas (BA 6), with the visual condition extending more into left lateral precentral areas. There were no associations with functional property verification for living concepts. Our results provide strong support for anatomically separable representations of living and nonliving concepts, as well as visual feature knowledge of living objects, and against distributed accounts of semantic memory that view visual and functional features of living and nonliving objects as distributed across a common set of brain areas.

\section{INTRODUCTION}

Theoretical accounts of category-specific semantic deficits-in which concepts from living and nonliving domains are independently impaired-fall into two distinct classes. One posits anatomically separable representations for different types of semantic information, whereas the other assumes that all semantic knowledge is represented in a distributed fashion within the same regions, irrespective of type.

Among the advocates of the former, disagreement persists about how semantic information is subdivided: According to the sensory-functional theory (SFT), the perceptual and functional properties of concepts depend on different brain regions, and category-specific deficits are explained by the differential importance of these two types of information for living and nonliving

\footnotetext{
${ }^{1}$ Albert-Ludwigs-University Freiburg, ${ }^{2}$ National Institute of Neurological Disorders and Stroke, National Institutes of Health, ${ }^{3}$ University College London, ${ }^{4}$ Royal Free Hospital, ${ }^{5}$ University of Regensburg, ${ }^{6}$ Inselspital and University of Bern
}

concepts, together with selective lesions to visual or functional feature regions (Warrington \& Shallice, 1984). Variants of the sensory-functional theory have proposed that domain-specific subdivisions may exist within such feature-specific areas (McCarthy \& Warrington, 1988) or, more recently, that conceptual knowledge arises from feature knowledge stored in the areas critical to lexical, as well as perceptual, and motor representations (Barsalou, Kyle Simmons, Barbey, \& Wilson, 2003; Pulvermuller, 1999). In contrast, the domain-specific account proposed by Caramazza and Mahon (2003) and Caramazza and Shelton (1998) assumes that evolutionary pressures have given rise to anatomically separable, generally amodal systems, representing semantic knowledge about animals, vegetables, and artifacts.

Distributed theories do not postulate separable semantic stores for either categories or semantic features (Rogers et al., 2004; Moss \& Tyler, 2000; Devlin, Gonnerman, Andersen, \& Seidenberg, 1998; Gonnerman, Andersen, Devlin, Kempler, \& Seidenberg, 1997; Caramazza, Hillis, \& Rapp, 1990) but account for categoryspecific deficits by appealing to differences in concept 
structure: the more co-occurring ("intercorrelated") features contributing to a concept's representation, the less likely that concept is to become degraded by partial damage to distributed representations. A different composition of feature co-occurrences in living and nonliving concepts has been proposed as the basis of differential impairments (Moss \& Tyler, 2000; Devlin et al., 1998; Gonnerman et al., 1997; Caramazza et al., 1990).

Neuropsychological studies of cohorts of patients with Alzheimer's disease (AD) have shown that semantic processing is impaired more frequently and deteriorates more rapidly for living concepts than for those in the nonliving domain. Garrard et al. (2001) and Garrard, Patterson, Watson, and Hodges (1998) argued that the category-specific patterns emerging at different stages of $\mathrm{AD}$ were because of the impact of regional distribution of pathology on the representation of sensory and functional information. Apart from a small subset of individual cases with available neuropathology, however, no hard neuroanatomical evidence was available to back up this claim. More recently, correlations between in vivo measures of regional pathology such as 18-fluorodeoxyglucose positron emission tomography (FDG-PET) or quantitative magnetic resonance imaging (MRI) and functional indices of semantic memory integrity in $\mathrm{AD}$ have been used to identify regions important to picture naming and nonverbal semantic tasks (Zahn et al., 2004; Hirono et al., 2001; Desgranges et al., 1998; Grossman et al., 1997, 2004). The technique provides a novel opportunity to test Garrard et al.'s hypothesis on a larger scale.

The aim of the present study was therefore to correlate information from FDG-PET - a sensitive and valid measure of regional brain function in $\mathrm{AD}$ (Herholz et al., 2002) — with performance on an experimental semantic task requiring knowledge of the sensory and functional feature knowledge of living and nonliving concepts. Only mild to moderate $\mathrm{AD}$ patients were included, so that semantic impairments would not be confounded with overall disease severity. We chose a feature verification task, which required patients to answer simple questions about the visual (e.g., "a zebra has stripes") and functional properties (e.g., "an axe chops") of object concepts. This task has a number of advantages over conventional semantic tasks such as picture naming: first, it may be more sensitive to category-specific impairments than picture naming (Laws \& Sartori, 2005); second, it allows visual and functional knowledge of living and nonliving concepts to be specifically and separately probed; finally, the fact that only the responses "true" or "false" are required, reduces the likelihood of confounds between experimental conditions and difficulties of lexical retrieval or word production.

The central assumption was that regions in which metabolism correlates with performance on each of the four conditions (living visual, living functional, nonliving visual, nonliving functional) are critical to the represen- tation of that specific kind of semantic information. We would further contend that although activation studies of normal subjects identify a set of brain regions that are involved in a particular task, the functional lesion approach reveals areas that are necessary for successful performance (Price, Mummery, Moore, Frakowiak, \& Friston, 1999) and, as such, represents an indispensable adjunct to this methodology.

We tested the following predictions from competing theories of semantic memory organization and its impairment in $\mathrm{AD}$ :

(a) According to the sensory-functional theory, brain areas necessary for the representation of visual and functional feature knowledge are clearly separable. Subregions within each of these areas may be differentially important for living and nonliving concepts.

(b) The domain-specific account predicts the existence of separable brain areas underpinning the representation of living and nonliving concepts with knowledge of the perceptual and functional features subserved by the same brain regions for each category.

(c) Theories of the distributed form would predict largely overlapping brain regions necessary for all types of knowledge relating to both living and nonliving concepts, although damage to different types of feature may vary according to the overall extent of dysfunction.

\section{METHODS}

\section{Patients}

Sixteen mild to moderate $\mathrm{AD}$ patients (all right-handed; 9 women; mean age $=67.7$ years, $S D=8.5$ years; mean years of schooling, 9.4, $S D=2.0$; mean Mini Mental State Examination $[\mathrm{MMSE}]$ score $=23.1, S D=2.9$; Clinical Dementia Rating score $=1$ in 11 patients and Clinical Dementia Rating score $=2$ in 5 patients) fulfilling the criteria of the National Institute of Neurological and Communicative Diseases and Stroke/Alzheimer's Disease and Related Disorders Association (McKhann et al., 1984) for probable $\mathrm{AD}$ and not fulfilling revised consensus criteria for frontotemporal dementia (Neary et al., 1998) were recruited through the Memory Clinic at the University of Freiburg. In one patient, a history of delusions and cognitive fluctuation raised the possibility of comorbid Lewy body disease (McKeith et al., 1996). His semantic memory test profile was within the range (mean $\pm 1.5 S D$ ) of the other patients in the group. Neuropsychological evaluation revealed consistent impairments of verbal and nonverbal delayed recall in all patients with additional naming or visuoconstructive deficits in different subgroups of patients (see Table 1). MRI revealed changes of diffuse and symmetrical volume 
Table 1. Results of Standard Neuropsychological Test Examinations

\begin{tabular}{lcccccc}
\hline & \multicolumn{5}{c}{ CERAD Test Battery (z Scores) } \\
\cline { 2 - 7 } & $\begin{array}{c}\text { Boston } \\
\text { Naming }\end{array}$ & $\begin{array}{c}\text { Category } \\
\text { Fluency }\end{array}$ & $\begin{array}{c}\text { Word List } \\
\text { Immediate Recall }\end{array}$ & $\begin{array}{c}\text { Delayed Word } \\
\text { List Recall }\end{array}$ & $\begin{array}{c}\text { Word Recognition } \\
\text { Rigures }\end{array}$ & $\begin{array}{c}\text { Drawing } \\
\text { Figure } \\
\text { Recall }\end{array}$ \\
\hline $\begin{array}{l}\text { No. of patients with } z \leq-1.0 \\
\text { (maximum: } n=16)\end{array}$ & 8 & 14 & 16 & 16 & 13 & 10 \\
Mean & -1.28 & -1.93 & -3.01 & -2.65 & -2.37 & -1.40 \\
SD & 1.24 & 0.74 & 1.00 & 0.61 & -2.36 \\
\hline
\end{tabular}

Results of the subtests of the CERAD test battery are based on standardized $z$ scores: mean $=0, S D=1 ;$ standardized age- and education-corrected German norms (Berres et al., 2000).

loss and bilateral hippocampal atrophy, together with minimal white matter lesions in some cases but no evidence of other pathology. Other causes of cognitive decline had been excluded based on routine blood tests. None of the patients had a history of stroke, other neurological disease, or major or recurrent psychiatric symptomatology, including substance abuse, before onset of dementia. All were native speakers of German. None of the patients had received cholinesterase inhibitors or cholinergic medication during the study; four patients were taking selective serotonin reuptake inhibitors and two were taking an atypical neuroleptic drug (quetiapine).

\section{Normal Controls}

Fourteen healthy right-handed volunteers ( 7 women; mean MMSE $=29.3, S D=1.1)$ matched to the patient group for age and years of schooling ( $p>.4$, MannWhitney $U$ test), without history of central nervous system or psychiatric disease, substance abuse, or psychotropic medication, provided control data for the experimental semantic tasks described below. All performed at normal levels $(z>-1)$ on the Consortium to Establish a Registry for Alzheimer's Disease (CERAD) test battery (a comprehensive standardized neuropsychological test battery for the diagnosis of dementia; German norms from Berres, Monsch, Bernasconi, Thalmann, \& Stahelin, 2000). Because of local ethics regulations, no age-matched control group was available for the PET study, so data from a group of 12 healthy normal subjects without psychiatric or neurological diseases or psychotropic medication $(7$ women; mean age $=$ 48 years, $S D=16$ years) were used. The most important aspect of the PET analysis (parametric regression), however, did not require control data.

\section{Semantic Verification Task}

A set of 192 simple propositions of the form "a zebra has stripes" or "an axe chops" were read aloud. Half of the propositions were true, and half were false, and subjects were simply required to make a verbal "true-or-false" decision.

The properties used in this test were taken from responses on a feature-generation task performed by a nonoverlapping group of 60 healthy volunteers (mean age $=27.1$ years, $S D=10.9$ ). For this task, words for 120 concepts (60 living and 60 nonliving) were selected from Snodgrass and Vanderwart's (1980) set. The words were divided into two sublists of 60 words (30 living and 30 nonliving), each of which was given to a subgroup of 30 controls. Controls were asked first to perform a free forward word association task by writing down the first word that came to mind after reading each object name. The percentage of subjects naming a word in response to a given object name yielded a measure of "forward associativity". Subjects were then instructed to write down between four and eight properties commonly attributed to each concept in turn. Each property was assigned a "dominance" value, equivalent to the proportion of subjects generating it in response to a word (Ashcraft, 1978). Feature distinctiveness was determined as the proportion of same-domain concepts for which the feature was generated.

Properties with dominance values of less than 15\% were discarded, and 96 selected from the remainder such that one visual and one functional property were associated with each of 24 living and 24 nonliving concepts. Living and nonliving concept words and visual and functional feature words were matched for spoken and written word frequency and syllable length using the CELEX lexical database (www.mpi.nl/world/celex/). Feature words were also matched across domain and across type by dominance and distinctiveness. All concept-feature pairs had less than $15 \%$ associativity. The combination of feature distinctiveness and feature dominance provides information comparable to the "feature relevance" measure of Sartori and Lombardi (2004). An equal set of distracter statements was formed by pseudorandom recombination of the selected properties with concepts to make a total of 192 statements in the task. Properties of living concepts were recombined with living concepts and nonliving properties with nonliving concepts only. 
The feature verification task was administered to 14 cognitively normal age- and education-matched controls. To equate the item difficulty across stimulus conditions a subset of 128 statements with high response consistency ( $>90 \%$ agreement) per item across normal controls was selected. The properties of the final 128 items used in the task are summarized in Table 2.

\section{Semantic Memory Test Battery}

Semantic memory integrity was documented using a German-language version of the semantic memory test battery described by Hodges, Salmon, and Butters (1992). The battery, described in detail by Zahn et al. (2004), is based on a set of 48 line drawings and associated concept names from Snodgrass and Vanderwart's (1980) set. Half the items are drawn from the living and half from the nonliving domain, matched for prototypicality, familiarity, visual complexity, spoken frequency, and syllable length. Subjects are presented with 48 line drawings for naming and with 48 arrays containing a target and within-category foils, for spoken word-topicture matching. Half of the items were presented within an array of 3, the other half within an array of 6 items. Subjects were also asked to produce as many exemplars of the following categories in a fixed order for 1 min each: land animals, clothing, vegetables, vehicles, insects, kitchen items, fruits, and musical instruments. The sum of correct, nonrepeated responses was recorded. The picture version of the Pyramids and Palm Trees (PPT) test (Howard \& Patterson, 1992) was administered as a nonlinguistic test of associative semantic knowledge.

\section{Positron Emission Tomography Imaging}

The PET procedure was performed according to previously defined standards (Juengling, Kassubek, \& Otte, 2000). Patient and control participants were allowed to rest in an acoustically isolated and dimmed room for at least 10 min before injection of $200 \pm 20 \mathrm{MBq}$ 18-FDG and for another $20 \mathrm{~min}$ during the uptake period. Participants were then transferred to the scanner (Siemens, Erlangen, Germany, CTI ECAT exact tomograph, $10.8 \mathrm{~cm}$ field of view, $6.8 \mathrm{~mm}$ full width half maximum), with their heads positioned relative to the orbitomeatal line. Image acquisition began 30 min after injection. Six dynamic frames were acquired, each of 5-min duration. Images were reconstructed using filtered back-projection (Shepp-Logan filter; cutoff $=0.35$ cycles $/$ pixel). Attenuation correction was performed using the standard mathematical algorithm implemented in ECAT software. The dynamic frames were then checked for motion artifacts and summed to generate a single data set of 31 transaxial planes.

For analysis using Statistical Parametric Mapping (SPM2, www.fil.ion.ucl.ac.uk), image data were converted to
ANALYZE format, and automated spatial normalization was performed to realign the data set to a common 3-D stereotaxic space using the Montreal Neurological Institute template (Friston, Holmes, \& Worsley, 1995). Before voxel-based analysis, images were smoothed using an $18 \times 18 \times 18$-mm Gaussian kernel to account for interindividual anatomical variability. The global cerebral metabolic rate for glucose (gCMRGlc) was normalized to a mean of $50 \mu \mathrm{mol} / 100 \mathrm{~mL} / \mathrm{min}$. The normalized FDGPET data of the patients were compared with healthy subjects by computing pixel-by-pixel $t$ statistics for detection of hypometabolic areas (Signorini et al., 1999). For anatomical identification, the coordinates derived from the Montreal Neurological Institute template were transformed using the appropriate algorithm (cf. www.mrccbu.cam.ac.uk/Imaging/mnispace.html) to comply with the original grid by Talairach and Tournoux. All areas exceeding a voxel threshold level of $z>3.09$ and $p=.001$, uncorrected, and a size of $>15$ voxels are reported in the group comparison.

Percent correct scores on each condition of the semantic verification task were entered as covariates of interest in the within-patient group parametric regression analysis with the aim of identifying regions showing decreased metabolism associated with low performance. For covariance analysis, voxel clusters with $t$ values corresponding to $p<.01$ in a single test and a minimum cluster size of 15 voxels were displayed as projected on lateral views of a standard brain (Figure 3). Only regions with a voxel significance level of $p<.001, z>3.09$, and a cluster size of $>15$ voxels at $p=.01$ are reported in Table 4 and discussed below.

\section{RESULTS}

\section{Neuropsychology}

\section{Background Neuropsychology}

As a group, the $\mathrm{AD}$ patients showed severe impairments of direct and delayed verbal as well as nonverbal recall and verbal recognition in the CERAD test battery (Table $1, z<-2 S D$ of age- and education-matched norm population mean). Boston Naming Test and figure drawing group means were in the less severely impaired range $(z<-1)$. Individual case analyses showed most consistent impairments in memory and fluency subtests; Boston Naming Test and figure drawing were impaired in different subgroups of patients.

\section{Semantic Memory Test Results}

Table 3 gives details of the patients' and normal group's performance in the semantic memory tests. On a group basis, $\mathrm{AD}$ patients performed significantly lower than controls on all semantic memory measures $(p=.05)$. Except for the PPT test and the nonliving functional condition of the verification task, all comparisons also 
Table 2. Psycholinguistic Description of the Semantic Verification Task

\begin{tabular}{|c|c|c|c|c|c|c|c|c|c|c|c|}
\hline & $\begin{array}{c}\text { Category } \\
\text { Ranks, Battig } \\
\text { Montague }\end{array}$ & $\begin{array}{c}\text { Syllables } \\
\text { Object } \\
\text { Name }\end{array}$ & $\begin{array}{l}\text { Written Word } \\
\text { Frequency } \\
\text { Object Name }\end{array}$ & $\begin{array}{l}\text { Spoken Word } \\
\text { Frequency } \\
\text { Object Name }\end{array}$ & $\begin{array}{c}\text { Feature } \\
\text { Distinctiveness }\end{array}$ & $\begin{array}{c}\text { Feature } \\
\text { Dominance }\end{array}$ & $\begin{array}{l}\text { Written Word } \\
\text { Frequency } \\
\text { Feature Word }\end{array}$ & $\begin{array}{l}\text { Spoken Word } \\
\text { Frequency } \\
\text { Feature Word }\end{array}$ & Associativity & $\begin{array}{l}\text { Syllables } \\
\text { Feature } \\
\text { Word }\end{array}$ & $\begin{array}{c}\text { Mean Response } \\
\text { Agreement } \\
\text { per Item in } \\
\text { Normal Subjects* }\end{array}$ \\
\hline \multicolumn{12}{|l|}{ Living visual } \\
\hline Mean & 14.42 & 1.84 & 98.00 & 5.94 & 0.044 & 0.390 & 668.19 & 55.12 & 0.029 & 1.66 & 0.986 \\
\hline$S D$ & 14.97 & 0.77 & 115.44 & 9.92 & 0.044 & 0.206 & 1249.13 & 107.32 & 0.045 & 0.70 & 0.028 \\
\hline \multicolumn{12}{|c|}{ Living functional } \\
\hline Mean & 15.73 & 2.09 & 63.75 & 2.28 & 0.033 & 0.389 & 277.53 & 19.19 & 0.028 & 1.56 & 0.984 \\
\hline$S D$ & 17.35 & 0.73 & 73.91 & 2.14 & 0.028 & 0.181 & 498.41 & 41.19 & 0.045 & 0.67 & 0.030 \\
\hline \multicolumn{12}{|l|}{ Nonliving visual } \\
\hline Mean & 12.48 & 2.00 & 63.44 & 4.78 & 0.047 & 0.372 & 465.13 & 41.38 & 0.010 & 1.81 & 0.982 \\
\hline$S D$ & 11.17 & 0.62 & 127.75 & 14.83 & 0.044 & 0.143 & 1083.56 & 95.70 & 0.020 & 0.64 & 0.031 \\
\hline \multicolumn{12}{|c|}{ Nonliving functional } \\
\hline Mean & 10.57 & 2.09 & 73.00 & 5.50 & 0.053 & 0.404 & 436.72 & 43.50 & 0.015 & 1.78 & 0.993 \\
\hline$S D$ & 9.73 & 0.69 & 127.09 & 14.76 & 0.059 & 0.150 & 634.42 & 74.94 & 0.022 & 0.87 & 0.021 \\
\hline $\begin{array}{l}p \text { values } \\
\text { Kruskal-Wallis, } \\
\text { asymptotic }\end{array}$ & $0.799, n s$ & $0.434, n s$ & $0.241, n s$ & $0.020, n s$ & $0.794, n s$ & $0.731, n s$ & $0.524, n s$ & $0.140, n s$ & $0.516, n s$ & $0.448, n s$ & $0.415, n s$ \\
\hline
\end{tabular}

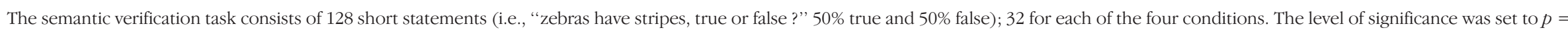

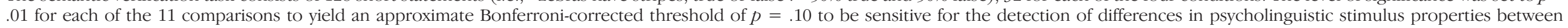
conditions.

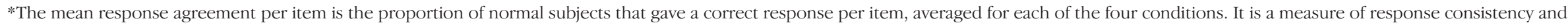
relative item difficulty. 
Table 3. Results of the Semantic Memory Tests

\begin{tabular}{|c|c|c|c|c|c|c|c|c|c|c|c|c|c|c|c|c|}
\hline & $\begin{array}{l}\text { Fluency } \\
\text { Living }\end{array}$ & $\begin{array}{c}\text { Fluency } \\
\text { Nonliving }\end{array}$ & $\begin{array}{c}\text { Fluency Difference } \\
\text { (Living - Nonliving) }\end{array}$ & $\begin{array}{l}\text { Word-Picture } \\
\text { Matching }\end{array}$ & Living & Nonliving & $\begin{array}{c}\text { Naming } \\
\text { without } \\
\text { Phonemic } \\
\text { Cue }\end{array}$ & $\begin{array}{l}\text { Naming } \\
\text { with } \\
\text { Phonemic } \\
\text { Cue }\end{array}$ & $\begin{array}{l}\text { Naming } \\
\text { Living }\end{array}$ & $\begin{array}{c}\text { Naming } \\
\text { Nonliving }\end{array}$ & $\begin{array}{c}\text { PPT } 3 \\
\text { Pictures }\end{array}$ & $\begin{array}{c}\text { Semantic } \\
\text { Verification }\end{array}$ & $\begin{array}{l}\text { Living } \\
\text { Visual }\end{array}$ & $\begin{array}{c}\text { Living } \\
\text { Functional }\end{array}$ & $\begin{array}{l}\text { Nonliving } \\
\text { Visual }\end{array}$ & $\begin{array}{l}\text { Nonliving } \\
\text { Functional }\end{array}$ \\
\hline \multicolumn{17}{|c|}{ Normal group $(n=14)$} \\
\hline Min & 34 & 40 & -26 & 98 & 96 & 100 & 96 & 98 & 96 & 96 & 88 & 97 & 94 & 97 & 94 & 94 \\
\hline Max & 61 & 69 & 12 & 100 & 100 & 100 & 100 & 100 & 100 & 100 & 100 & 100 & 100 & 100 & 100 & 100 \\
\hline Mean & 50.4 & 56.3 & -5.9 & 99.9 & 99.7 & 100.0 & 98.9 & 99.9 & 99.1 & 98.6 & 96.0 & 98.7 & 98.7 & 98.4 & 98.2 & 99.3 \\
\hline$S D$ & 7.9 & 11.1 & 10.2 & 0.5 & 1.1 & 0.0 & 1.5 & 0.5 & 1.7 & 2.0 & 3.8 & 0.9 & 2.4 & 1.6 & 2.0 & 1.8 \\
\hline Normal cutoff & 34 & 34 & $<-26$ to $>+15$ & 96 & 92 & 96 & 94 & 96 & 92 & 92 & 88 & 96 & 91 & 94 & 91 & 91 \\
\hline \multicolumn{17}{|c|}{ Patient group $(n=16)$} \\
\hline Min & 13 & 13 & -12 & 90 & 79 & 96 & 50 & 63 & 50 & 50 & 56 & 75 & 69 & 69 & 72 & 88 \\
\hline Max & 46 & 44 & 2 & 100 & 100 & 100 & 100 & 100 & 100 & 100 & 96 & 98 & 97 & 100 & 100 & 100 \\
\hline Mean & 25.0 & 29.0 & -4.0 & 98.4 & 97.4 & 99.2 & 83.3 & 90.1 & 84.1 & 82.0 & 86.4 & 91.5 & 89.1 & 92.0 & 90.6 & 94.5 \\
\hline$S D$ & 9.0 & 8.9 & 4.6 & 0.0 & 0.1 & 0.0 & 15.2 & 11.6 & 16.5 & 16.4 & 12.8 & 5.9 & 7.9 & 8.4 & 6.9 & 3.9 \\
\hline $\begin{array}{l}\text { No. of patients < } \\
\text { cutoff }\end{array}$ & 13 & 11 & 0 & 3 & 1 & 3 & 12 & 10 & 12 & 11 & 6 & 12 & 13 & 10 & 13 & 9 \\
\hline $\begin{array}{l}\text { Patients }<\text { normal } \\
\text { controls } p \text { values, } \\
\text { Mann-Whitney } \\
U \text { test, } \\
\text { two-tailed }\end{array}$ & $0.0001^{*}$ & $0.0001^{*}$ & $0.4000, n s$ & $0.0001^{*}$ & $0.0001^{*}$ & $0.0001^{*}$ & $0.0001^{*}$ & $0.001 *$ & $0.001 *$ & $0.0001 *$ & 0.009 & $0.0001^{*}$ & $0.0001^{*}$ & 0.028 & $0.001 *$ & $0.001 *$ \\
\hline
\end{tabular}

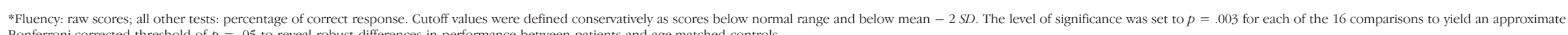
Bonferroni-corrected threshold of $p=.05$ to reveal robust differences in performance between patients and age-matched controls. 
survived a more stringent Bonferroni-corrected threshold ( $p=.003$; equivalent to an approximate Bonferronicorrected threshold of $p=.05$ ). On an individual case basis, more than two thirds of the $\mathrm{AD}$ patients were below the normal cutoff score (below normal mean $-2 S D$ and below normal range) in the following tests: semantic word fluency, picture naming, and semantic verification. Word-picture matching was above the normal cutoff score in 13 of 16 patients, and nonverbal semantic memory (PPT test) was below the cutoff in 6 of 16 patients.

\section{Semantic Verification Task Results}

As a group, patients performed at a lower level than controls in all task conditions (Table 3). The scores of 13 of 16 patients fell below the normal cutoff in the visual conditions; of 16 patients, 10 were below cutoff in the living functional conditions and 9 in the nonliving functional condition (Table 3). Normal subjects performed at ceiling level all conditions. Figure 1 shows the comparative levels of accuracy (percentage of correct responses) achieved by patients in the four conditions of the semantic verification task. A nonparametric one-way analysis of variance over the four task condi- tions revealed no significant effect of task condition on performance $\left[\chi^{2}(3)=7.5, p=.06, n s\right.$, Friedman test, asymptotic].

Figure 2 displays individual scores in the semantic verification task plotted against scores on naming, PPT, and MMSE. There were highly significant associations (Spearman's $\rho$, two-tailed significance) between performance on the verification task and both naming $(\rho=0.75, p=.001)$ and PPT $(\rho=0.79, p=.0001)$, but no such relationship with MMSE $(\rho=0.28, p=.30)$.

Dissociations of performance between categories and/ or features were sought using $\chi^{2}$ statistics on each patient's scores. Only one patient showed a significant dissociation at $p<.05$, arising from a greater number of errors with visual feature questions distributed evenly across living and nonliving conditions. The same patient's naming performance showed a trend toward a category-specific difference with more errors for nonliving (79\% correct) than for living concepts (96\% correct; Fisher's Exact Test, $p=.09)$. Two more patients showed category differences in the naming task, one with a trend toward a greater deficit for living concepts (58\% vs. 83\% correct; Fisher's Exact Test, $p=.055$ ), and the other with the reverse pattern (54\% vs. 83\% correct; Fisher's Exact Test, $p=.03)$. There were no dissociated

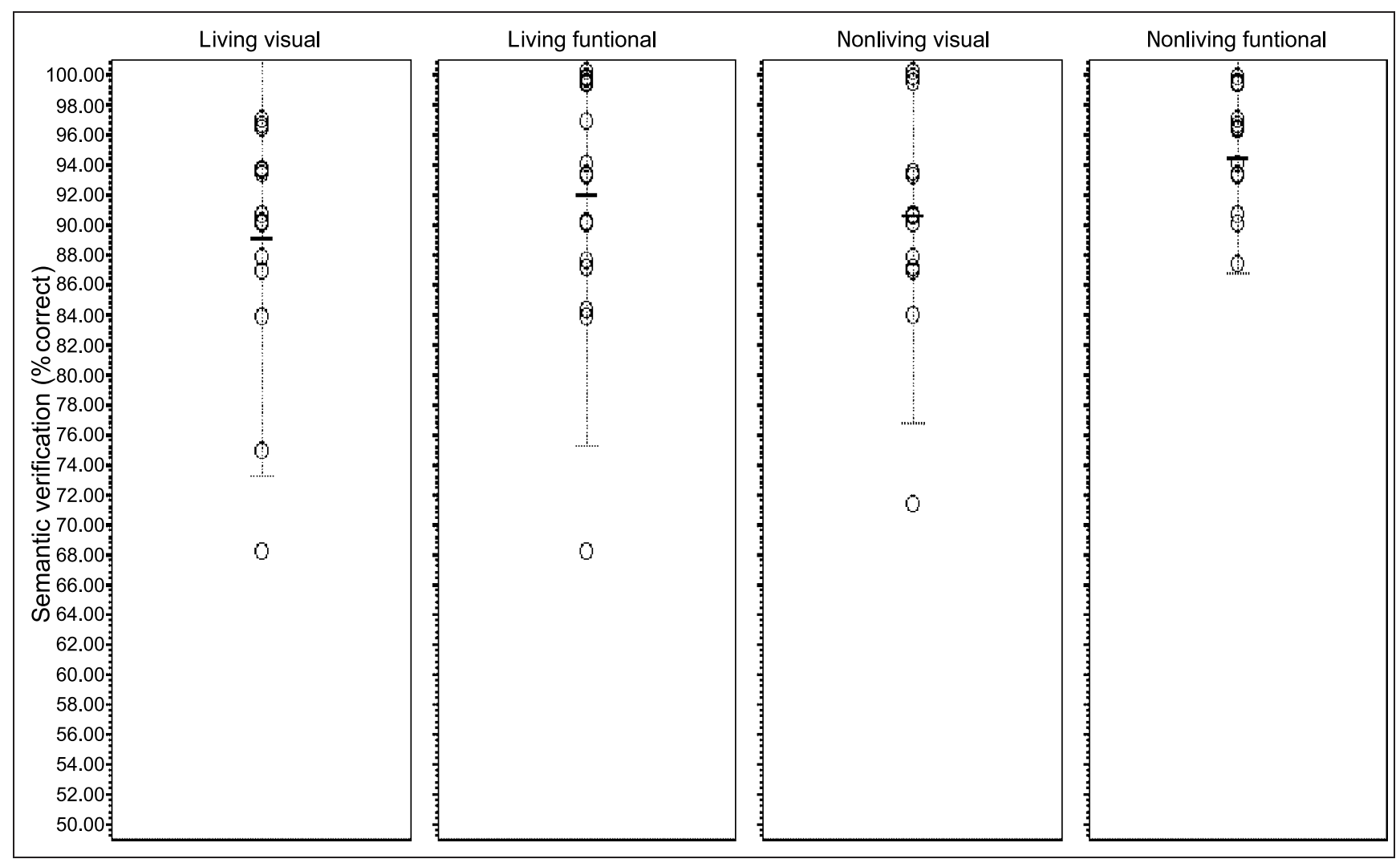

Figure 1. Accuracy in the four conditions of the semantic verification task in patients. The percentage of correct responses of AD patients $(n=16)$ is plotted for each condition. Error bars represent mean $\pm 2 S D$. Dots are jittered for graphical display. $50 \%$ correct responses $=$ chance performance. There were no significant differences in performance in the four conditions in patients [nonparametric one-way analysis of variance: $\chi^{2}(3)=7.5, p=.06, n s$, Friedman test, asymptotic]. 
Table 4. PET, Group Comparison and Regression Analyses

\begin{tabular}{|c|c|c|c|c|c|c|}
\hline Hemisphere & Area & $x$ & $y$ & $z$ & $B A$ & $z$ Score \\
\hline \multicolumn{7}{|l|}{$A D<N C$} \\
\hline$L$ & Middle frontal gyrus & -54 & 21 & 36 & $9 / 8$ & 4.25 \\
\hline $\mathrm{L}$ & Inferior temporal gyrus & -44 & -34 & -24 & 20 & 4.42 \\
\hline $\mathrm{L}$ & Anterior superior temporal gyrus & -44 & 2 & 2 & 22 & 3.28 \\
\hline $\mathrm{L}$ & Superior temporal gyrus & -44 & -21 & 7 & 22 & 3.47 \\
\hline $\mathrm{L}$ and $\mathrm{R}$ & Angular gyrus & -52 & -73 & 26 & $39 / 7$ & 4.85 \\
\hline$L$ and $R$ & Posterior cingulate & 0 & -47 & 36 & 31 & 4.58 \\
\hline $\mathrm{R}$ & Middle frontal gyrus & 53 & 19 & 36 & $9 / 8$ & 4.27 \\
\hline $\mathrm{R}$ & Inferior temporal gyrus & 50 & -30 & -25 & 20 & 3.95 \\
\hline $\mathrm{R}$ & Posterior superior temporal sulcus & 48 & -50 & 12 & $22 / 21$ & 3.44 \\
\hline
\end{tabular}

\section{Living functional}

No cluster $p=.001$

Living visual

L

Posterior fusiform gyrus

$\begin{array}{ll}-26 & -70\end{array}$

2

$19 / 37$

Nonliving functional

L

L

Nonliving visual

L

$\mathrm{L}$ and $\mathrm{R}$

$\mathrm{R}$

Side maxima for large clusters are in italics. $\mathrm{NC}=$ normal controls. All areas exceeding a voxel threshold level of $p=.001$, uncorrected, and a cluster size of $>15$ voxels are reported (SPM2). One patient had scores below the patient group mean $-2 S D$ on three conditions of the verification task (see Figure 1). To rule out the possibility that our regression analyses were disproportionately influenced by this extreme case we repeated the analysis after excluding the outlier. All reported regions were confirmed in the reanalysis.

patterns of performance on word picture matching or fluency in any of the patients.

\section{8-Fluorodeoxyglucose Positron Emission Tomography}

\section{Alzheimer's Disease versus Normal Control Group Comparison}

The group comparison shows a typical pattern of hypometabolism in $\mathrm{AD}$ patients relative to normal controls in the bilateral dorsolateral prefrontal cortices (Brodmann's area [BA] 8/9), bilateral inferior temporal gyri (BA 20), the left anterior superior temporal gyrus (BA 22), the right posterior superior temporal sulcus (BA 22/21), bilateral angular gyri (BA 39/7), and bilateral posterior cingulate gyri/precuneus (BA 31) (Figure 3, Table 4).

\section{Within-Alzheimer's Disease Patient Group Regression Analyses}

The main focus of this article is the result of the within$\mathrm{AD}$ patient group regression analyses, independent of normal controls. These analyses identify brain regions in the $\mathrm{AD}$ group where glucose metabolism was positively correlated with performance in the respective condition of the semantic verification task (living visual, living functional, nonliving visual, nonliving functional). Figure 3 shows 3-D projections of these significantly correlated regions on a more lenient level of significance $(p=.01)$ to give an impression of the extension of areas. We will only report and discuss regions in the text and Table 4, however, that achieved a more stringent level of significance ( $p=.001,15$ voxels).

Performance on verification of the visual properties of living things was significantly correlated with metabolism 


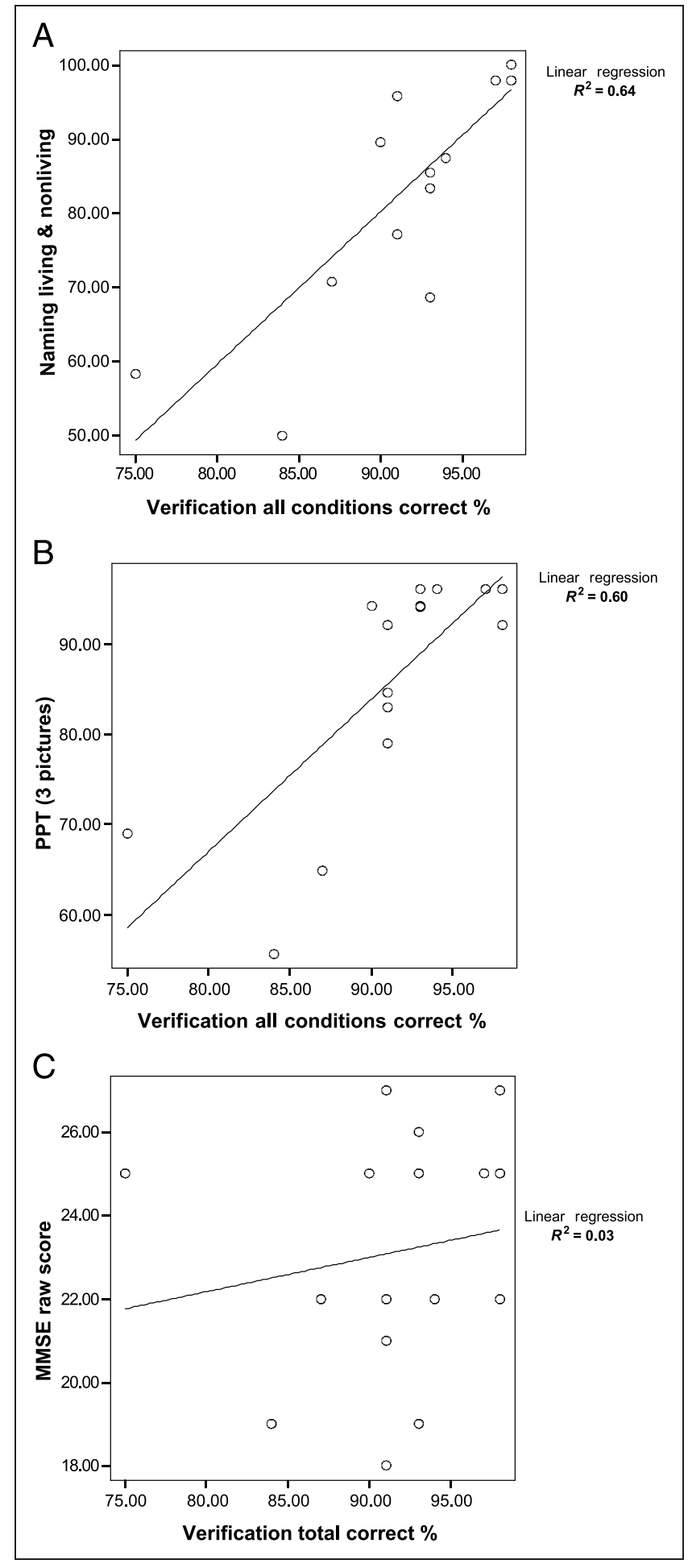

Figure 2. Dependence between patients' performance in the semantic verification task in comparison to other semantic tasks as well as overall cognitive status. Linear regression of accuracy in the semantic verification task is plotted against (A) overall naming (semantic memory test battery) and (B) nonverbal semantic memory (PPT test, threepicture version), accuracy (percentage correct responses), as well as (C) MMSE raw scores in AD patients $(n=16)$. Linear regression $R^{2}$ scores are depicted. There were highly significant associations (Spearman's $\rho$, twotailed significance) between performance on the verification task and both naming $(\rho=0.75, p=.001)$ and PPT $(\rho=0.79, p=.0001)$, but there was no such relationship with MMSE $(\rho=0.28, p=.30)$. in the left posterior fusiform gyrus (BA 37/19), whereas performance with both visual and functional properties of the nonliving concepts was significantly associated with metabolism in left anterior temporal (BA 20/38) and bilateral precentral/premotor regions (BA 4/6). The right frontal pole (BA 10) was associated with the nonliving visual properties only. No area exceeded threshold for the living functional condition. The comparison of the extensions of significantly associated areas (Figure 3) shows a more pronounced extension within the left lateral precentral cortex for the nonliving visual condition and a larger extension of premotor hypometabolism into the right hemisphere for the nonliving functional condition.

\section{DISCUSSION}

The study reported here was designed to identify correlations between regions of cortical hypometabolism and performance on a semantic feature verification task in which conceptual domain membership (living vs. nonliving) was crossed with type of knowledge probed (visual vs. functional). The principal motivation for the study was to test the contrasting predictions of a number of theoretical models of semantic organization, concerning the relationship between living and nonliving concepts on the one hand, and visual and functional knowledge on the other. The study's major findings can be summarized as the association of (a) impaired knowledge of the visual properties of living concepts with hypometabolism in the posterior fusiform gyrus (BA 37/19) and (b) impaired knowledge of the visual and functional properties of nonliving concepts with hypometabolism in the left anterior temporal (BA 38/20) and motor/premotor areas (BA 4/6). Both findings are in keeping with a large body of previously published data linking brain regions with semantic categories and different feature types.

The left posterior fusiform region has been linked to visual property verification using functional MRI (Kan, Barsalou, Solomon, Minor, \& Thompson-Schill, 2003), and to noun imageability using PET (Wise et al., 2000), although neither study contrasted living and nonliving concepts. Thompson-Schill, Aguirre, Desposito, and Farah (1999) used a verbal property verification task to show activation of the posterior fusiform gyrus (BA 37) for all aspects of living things and for nonliving concepts when visual property knowledge was explicitly required. As Price et al. (1999) have pointed out, however, functional activation in normal subjects is likely to include regions that are involved in but not necessary for task performance. Thus, although the posterior fusiform gyrus might be activated for both living and nonliving concepts, the data reported here would suggest that it may be necessary only for judgments involving the visual properties of living things.

The association between knowledge of nonliving concepts and the anterior temporal lobe accords with 
Figure 3. Results of the group comparison $\mathrm{AD}$ patients versus normal controls (NC) (voxel significance level: $p=.001$, 15 voxels; first row) and the within-AD patient group regression analyses (AD) $(n=16)$ showing areas significantly associated with the percentage of correct responses in the condition of interest of the semantic verification task. Projections onto lateral views of a standard brain are shown (voxel significance level: $p=.01$ and 15 voxels extent threshold for this figure); only regions at a more stringent level of $p=.001$ and 15 voxels are listed in Table 4 and discussed in the text.

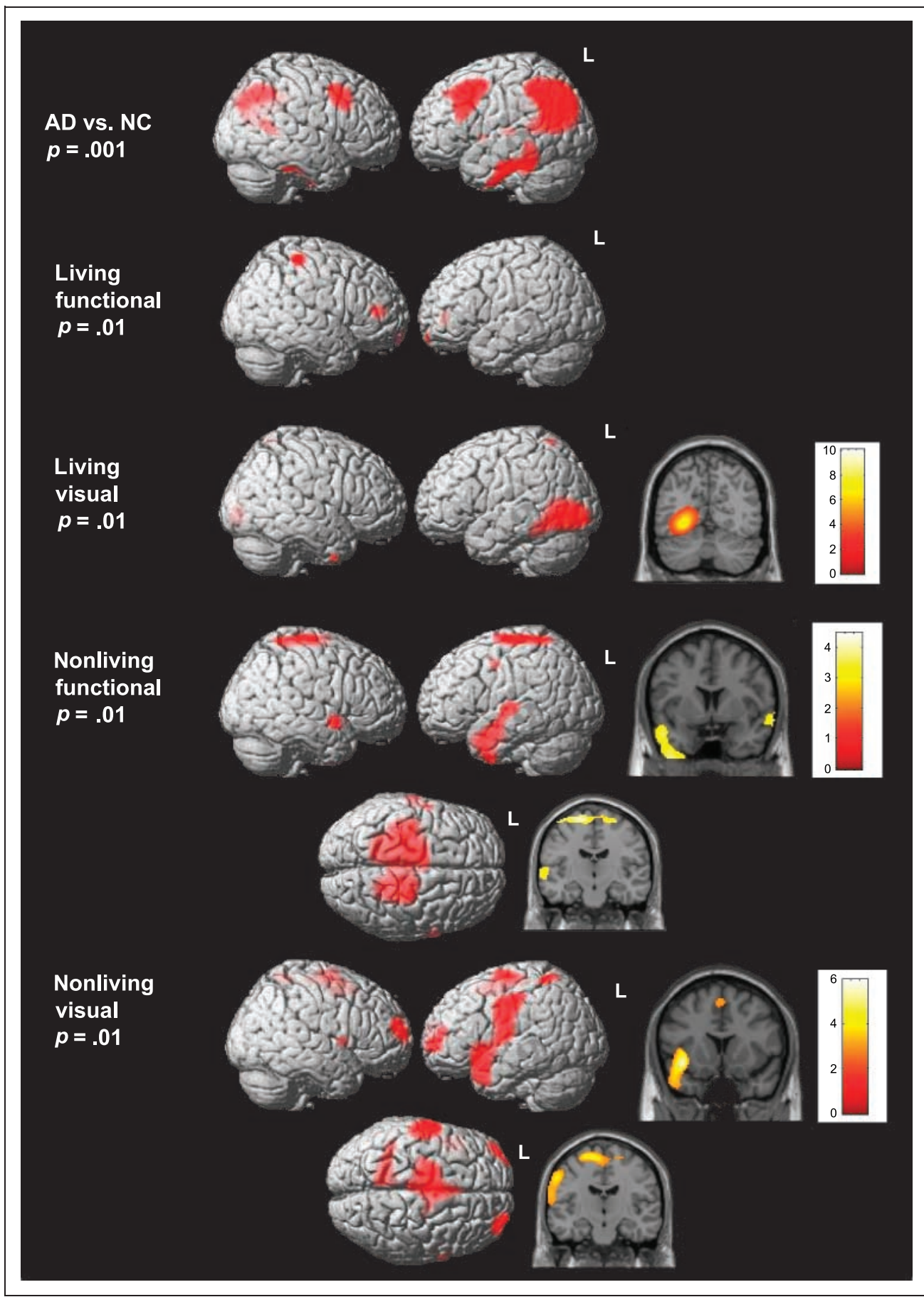

descriptions of patients with anterior temporal lobe resections who show selective naming impairments for both human actions (Lu et al., 2002) and nonliving items (Cappa, Frugoni, Pasquali, Perani, \& Zorat, 1998; Tippett, Glosser, \& Farah, 1996). The importance of anterior temporal cortex for semantic memory is well established: Its supramodal role in semantic knowledge can be inferred from the multimodal impairments characteristic of the syndrome of semantic dementia, which is associated with atrophy in anterior temporal regions (Davies et al., 2005; Rogers et al., 2004; Hodges, Bozeat,
Lambon Ralph, Patterson, \& Spatt, 2000). Semantic knowledge impairments in semantic dementia also impact on tool use, emphasizing the importance of the anterior temporal lobe for the representation of functional information (Hodges et al., 2000).

The importance of premotor areas for nonliving concepts accords with evidence from functional activation studies in normal subjects pointing to the involvement of left premotor cortex (BA 6) in the representation of tool and action knowledge (Martin \& Chao, 2001) as well as action perception (Rizzolatti, Fogassi, \& Gallese, 2002). 
Also, primary motor cortex (BA 4) is activated during semantic comprehension of verbs describing movement related actions (Hauk, Johnsrude, \& Pulvermuller, 2004). Finally, the dependence of visual knowledge for nonliving concepts on motor rather than visual areas is consistent with the idea that imagery of motor acts is involved in retrieving visual information about artifacts (review of "motor imagery" by Jeannerod \& Frak, 1999).

The implications of these anatomical patterns for rival theories of category specificity in $\mathrm{AD}$ are twofold. In the first place, it is clear that impairment of semantic knowledge for living and nonliving objects in $\mathrm{AD}$ patients resulted from regional dysfunction in anatomically separable brain areas. Second, higher order visual information in the left posterior fusiform region may relate specifically to living concepts. Neither of these findings can be accounted for by theories based on the assumption of a widely distributed supramodal semantic memory store.

By contrast, the predictions of Garrard et al. (1998, 2001), based on the patterns of performance in tasks assessing semantic knowledge for living and nonliving concepts in $\mathrm{AD}$, were, at least partially, corroborated. According to this account, dissociations of semantic knowledge for living and nonliving concepts should be because of differences in the regional distribution of pathology in $\mathrm{AD}$. Temporal neocortical regions, which are most subject to degenerative damage in $\mathrm{AD}$, are differentially important in the representation of living concepts and give rise to the more typical nonliving advantage in the earlier disease stages. Without in vivo anatomical support for a concomitant sensory-functional difference, however, Garrard et al. conceded that the patterns of performance could also be explained by assuming "evolutionarily adapted domain-specific knowledge systems subserved by distinct neural mechanisms" (Caramazza \& Shelton, 1998).

The importance of inferior temporal dysfunction in the impairment of living concept knowledge in $\mathrm{AD}$ is supported here by the finding of such an association within the posterior fusiform gyrus (BA 37/19). It is also in accordance with the literature on category-specific deficits for living things due to other causes (e.g., herpes simplex encephalitis, closed head injury) showing inferior temporal lobe involvement most frequently (Gainotti, 2000). The finding of a specific association of visual features alone with left temporal changes suggests in addition a link between visual feature knowledge and the impairments of living concept knowledge in $\mathrm{AD}$, as predicted by the sensory-functional, but not the domain-specific, theory. Our second finding of an association of nonliving but not living concept knowledge with anterior temporal and premotor cortical metabolism, however, is more difficult to reconcile with the sensory-functional theory. In this instance, the overlap of regions associated with visual and functional feature knowledge of nonliving objects may be better explained by the domain-specific hypothesis.
Our seemingly contradictory findings with regard to these two competing theoretical accounts of anatomically separable subdivisions for different types of semantic knowledge can be best explained within a more recent formulation of the domain-specific account (Caramazza \& Mahon, 2003). This hybrid model admits of the coexistence of supramodal domain-specific regions for animals, fruits/vegetables, and tools and additional unimodal feature-specific semantic regions. Indeed, a growing body of evidence from the cognitive neuropsychological literature suggests that impairments of living and nonliving object knowledge can occur in the absence of more pronounced effects of either visual or functional features (Caramazza \& Mahon, 2003; Laiacona, Capitani, \& Caramazza, 2003; Zannino, Perri, Carlesimo, Pasqualetti, \& Caltagirone, 2002; Lambon-Ralph, 1998). Moreover, visual feature knowledge can be impaired in patients without leading to category-specific effects for living concepts (Caramazza \& Mahon, 2003; Lambon-Ralph, 1998) - a pattern that, we note in passing, was exhibited by one of the patients in the present study. Our data thus accord with the heterogeneity of category-specific semantic disorders reported in the literature (Rosazza et al., 2003).

The finding of regional dysfunction within the premotor and anterior temporal cortex is in agreement with postmortem neurochemical studies that detected variable degrees of tau pathology in the anterior temporal areas (BA 20/38) and synaptic loss in the premotor area (BA 6) even at predementia stages of $\mathrm{AD}$ (Vermersch et al., 1995; Clinton, Blackman, Royston, \& Roberts, 1994). Previous studies in AD patients using regression analyses and global measures of semantic functions (naming and/or nonverbal impairment) have also shown associations with premotor (Grossman et al., 2004) and anterior temporal (Zahn et al., 2004) areas using voxel-based morphometry and FDG-PET, respectively. Functional disconnection (diaschisis) of the anterior temporal and motor/premotor regions caused by neurodegeneration within the posterior temporal or parietal association cortices also provide a plausible pathophysiological mechanism. The posterior temporal and parietal association cortex are highly connected to these regions (Creutzfeldt, 1983) and are severely and consistently affected by tangle neuropathology (Harasty, Halliday, Kril, \& Code, 1999; Braak \& Braak, 1991).

Our negative finding with regard to significant associations for functional knowledge of living objects with any brain area points to greater variability in the association of regional metabolism and task performance than in the other task conditions. Given the robust correlations of specific regional metabolism with performance in the other conditions, this negative finding is unlikely to be due simply to a lack of statistical power. An alternative explanation is that the knowledge required for the task was represented across multiple regions. This would be consistent with the heterogeneity characteristic 
of functional features of living objects, which may describe their use by man or animal, characteristic motion, environmental context, or general "encyclopedic knowledge," to name but a few. Thus, the a priori probability of linking this diverse group of features to a specific brain area might be expected to be lower. Future studies using tasks with more differentiated subclassifications of features as proposed by, for example, Cree and McRae (2003) may well reveal specific brain regions linked to subclasses of functional knowledge for living things.

Our findings of regional hypometabolism that is associated with semantic impairment in $\mathrm{AD}$ has to be interpreted in conjunction with evidence from other sources to rule out a functional age-related origin of these abnormalities. Neuroimaging studies and neuropathology showed abnormalities in AD patients compared with aged healthy controls in those regions that were associated with semantic memory dysfunction in our study (Zahn et al., 2005; Grossman et al., 2004; Herholz et al., 2002; Harasty et al., 1999; Clinton et al., 1994; Braak \& Braak, 1991). PET studies showed age effects primarily outside of temporal and premotor regions relevant to performance in our task (Herholz et al., 2002). Furthermore, our agematched control group performed almost perfectly on the semantic task. Thus, normal aging does not markedly affect explicit semantic memory and associated brain regions. In summary, this supports the conclusion that regional effects demonstrated in our $\mathrm{AD}$ group did not arise by functional age-related changes but by diseaserelated pathology. On a more cautious note, the robustness of our findings would undoubtedly benefit from further studies replicating the regional associations seen in the present sample and thus confirming consistent regional effects across different $\mathrm{AD}$ groups.

In conclusion, therefore, the findings of the present study support the view that semantic organization is characterized both by category-specific supramodal and unimodal feature-specific regions. It should be noted that these data neither demonstrate nor rule out the presence of category-specific subdivisions within the supramodal anterior temporal area, where visual and functional feature knowledge for nonliving things overlap. The findings would therefore be equally consistent with theories positing supramodal semantic stores without category-specific subdivisions for living and nonliving concepts that allow for additional feature-specific regions with category-specific subdivisions. To the best of our knowledge, however, no single cases have yet been described that would be consistent with either of these interpretations.

\section{Acknowledgments}

R. Z. was supported by a grant from the German Academy of Natural Scientists Leopoldina (BMBF-LPD 9901/8-122). We are grateful for the helpful suggestions of two anonymous reviewers.
Reprint requests should be sent to Roland Zahn, Cognitive Neuroscience Section, National Institute of Neurological Disorders and Stroke, National Institutes of Health, 5C205, Building 10, MSC 1440, 10 Center Drive, Bethesda, MD 20892 1440, or via e-mail: zahnr@ninds.nih.gov.

\section{REFERENCES}

Ashcraft, M. H. (1978). Property norms for typical and atypical items from 17 categories: A description and discussion. Memory \& Cognition, 6, 227-232.

Barsalou, L. W., Kyle Simmons, W., Barbey, A. K., \& Wilson, C. D. (2003). Grounding conceptual knowledge in modality-specific systems. Trends in Cognitive Sciences, 7 , 84-91.

Berres, M., Monsch, A. U., Bernasconi, F., Thalmann, B., \& Stahelin, H. B. (2000). Normal ranges of neuropsychological tests for the diagnosis of Alzheimer's disease. Studies in Health Technology and Informatics, 77, 195-199.

Braak, H., \& Braak, E. (1991). Neuropathological stageing of Alzheimer-related changes. Acta Neuropathologica (Berlin), 82, 239-259.

Cappa, S. F., Frugoni, M., Pasquali, P., Perani, D., \& Zorat, F. (1998). Category-specific naming impairment for artefacts: A new case. Neurocase, 4, 391-397.

Caramazza, A., Hillis, A., \& Rapp, B. (1990). The multiple semantics hypothesis: Multiple confusions? Cognitive Neuropsychology, 7, 161-189.

Caramazza, A., \& Mahon, B. Z. (2003). The organization of conceptual knowledge: The evidence from category-specific semantic deficits. Trends in Cognitive Science, 7, 354-361.

Caramazza, A., \& Shelton, J. R. (1998). Domain-specific knowledge systems in the brain the animate-inanimate distinction. Journal of Cognitive Neuroscience, 10, 1-34.

Clinton, J., Blackman, S. E., Royston, M. C., \& Roberts, G. W. (1994). Differential synaptic loss in the cortex in Alzheimer's disease: A study using archival material. NeuroReport, 5, 497-500.

Cree, G. S., \& McRae, K. (2003). Analyzing the factors underlying the structure and computation of the meaning of chipmunk, cherry, chisel, cheese, and cello (and many other such concrete nouns). Journal of Experimental Psychology: General, 132, 163-201.

Creutzfeldt, O. D. (1983). Cortex cerebri Leistung, strukturelle und funktionelle Organisation der Hirnrinde. Springer: Berlin.

Davies, R. R., Hodges, J. R., Kril, J. J., Patterson, K., Halliday, G. M., \& Xuereb, J. H. (2005). The pathological basis of semantic dementia. Brain, 128, 1984-1995.

Desgranges, B., Baron, J. C., de la Sayette, V., Petit-Taboue, M. C., Benali, K., Landeau, B., et al. (1998). The neural substrates of memory systems impairment in Alzheimer's disease. A PET study of resting brain glucose utilization. Brain, 121, 611-631.

Devlin, J. T., Gonnerman, L. M., Andersen, E. S., \& Seidenberg, M. S. (1998). Category-specific semantic deficits in focal and widespread brain damage: A computational account. Journal of Cognitive Neuroscience, 10, 77-94.

Friston, K. J., Holmes, A., \& Worsley, K. J. (1995). Statistical parametric maps in functional imaging: A general linear approach. Human Brain Mapping, 2, 189-280.

Gainotti, G. (2000). What the locus of brain lesion tells us about the nature of the cognitive defect underlying category-specific disorders: A review. Cortex, 36, 539-559.

Garrard, P., Lambon Ralph, M. A., Watson, P. C., Powis, J., Patterson, K., \& Hodges, J. R. (2001). Longitudinal profiles of semantic impairment for living and nonliving concepts 
in dementia of Alzheimer's type. Journal of Cognitive Neuroscience, 13, 892-909.

Garrard, P., Patterson, K., Watson, P. C., \& Hodges, J. R. (1998). Category specific semantic loss in dementia of Alzheimer's type. Functional-anatomical correlations from crosssectional analyses. Brain, 121, 633-646.

Gonnerman, L. M., Andersen, E. S., Devlin, J. T., Kempler, D., \& Seidenberg, M. S. (1997). Double dissociation of semantic categories in Alzheimer's disease. Brain and Language, 57, 254-279.

Grossman, M., McMillan, C., Moore, P., Ding, L., Glosser, G., Work, M., et al. (2004). What's in a name: Voxel-based morphometric analyses of MRI and naming difficulty in Alzheimer's disease, frontotemporal dementia and corticobasal degeneration. Brain, 127, 628-649.

Grossman, M., Payer, F., Onishi, K., White-Devine, T., Morrison, D., D'Esposito, M., et al. (1997). Constraints on the cerebral basis for semantic processing from neuroimaging studies of Alzheimer's disease. Journal of Neurology, Neurosurgery, and Psychiatry, 63, 152-158.

Harasty, J. A., Halliday, G. M., Kril, J. J., \& Code, C. (1999). Specific temporoparietal gyral atrophy reflects the pattern of language dissolution in Alzheimer's disease. Brain, 122, 675-686.

Hauk, O., Johnsrude, I., \& Pulvermuller, F. (2004). Somatotopic representation of action words in human motor and premotor cortex. Neuron, 41, 301-307.

Herholz, K., Salmon, E., Perani, D., Baron, J. C., Holthoff, V., Frolich, L., et al. (2002). Discrimination between Alzheimer dementia and controls by automated analysis of multicenter FDG PET. Neuroimage, 17, 302-316.

Hirono, N., Mori, E., Ishii, K., Imamura, T., Tanimukai, S., Kazui, H., et al. (2001). Neuronal substrates for semantic memory: A positron emission tomography study in Alzheimer's disease. Dementia and Geriatric Cognitive Disorders, 12, 15-21.

Hodges, J. R., Bozeat, S., Lambon Ralph, M. A., Patterson, K., \& Spatt, J. (2000). The role of conceptual knowledge in object use evidence from semantic dementia. Brain, 123, 1913-1925.

Hodges, J. R., Salmon, D. P., \& Butters, N. (1992). Semantic memory impairment in Alzheimer's disease: Failure of access or degraded knowledge? Neuropsychologia, 30, 301-314.

Howard, D., \& Patterson, K. (1992). The pyramids and palm trees test. Thames Valley Test Company: Flempton.

Jeannerod, M., \& Frak, V. (1999). Mental imaging of motor activity in humans. Current Opinion in Neurobiology, 9, 735-739.

Juengling, F. D., Kassubek, J., \& Otte, A. (2000).

Standardization of cerebral PET imaging in clinical neurological diagnostics. European Journal of Nuclear Medicine, 27, 98.

Kan, I. P., Barsalou, L. W., Solomon, K. O., Minor, J. K., \& Thompson-Schill, S. L. (2003). Role of mental imagery in a property verification task: fMRI evidence for perceptual representations of conceptual knowledge. Cognitive Neuropsychology, 20, 525-540.

Laiacona, M., Capitani, E., \& Caramazza, A. (2003). Category-specific semantic deficits do not reflect the sensory/functional organization of the brain: A test of the "sensory quality" hypothesis. Neurocase, 9, 221-231

Lambon-Ralph, M. A. (1998). Are living and non-living category-specific deficits causally linked to impaired perceptual or associative knowledge? Evidence from a category-specific double dissociation. Neurocase, 4 , 311-338.
Laws, K. R., \& Sartori, G. (2005). Category deficits and paradoxical dissociations in Alzheimer's disease and herpes simplex encephalitis. Journal of Cognitive Neuroscience, 17, 1453-1459.

Lu, L. H., Crosson, B., Nadeau, S. E., Heilman, K. M., Gonzalez-Rothi, L. J., Raymer, A., et al. (2002). Category-specific naming deficits for objects and actions: Semantic attribute and grammatical role hypotheses. Neuropsychologia, 40, 1608-1621.

Martin, A., \& Chao, L. L. (2001). Semantic memory and the brain: Structure and processes. Current Opinion in Neurobiology, 11, 194-201.

McCarthy, R. A., \& Warrington, E. K. (1988). Evidence for modality-specific meaning systems in the brain. Nature, 334 , 428-430.

McKeith, I. G., Galasko, D., Kosaka, K., Perry, E. K., Dickson, D. W., Hansen, L. A., et al. (1996). Consensus guidelines for the clinical and pathologic diagnosis of dementia with Lewy bodies (DLB): Report of the consortium on DLB international workshop. Neurology, 47, 1113-1124

McKhann, G., Drachman, D., Folstein, M., Katzman, R., Price, D., \& Stadlan, E. M. (1984). Clinical diagnosis of Alzheimer's disease: Report of the NINCDS-ADRDA Work Group under the auspices of Department of Health and Human Services Task Force on Alzheimer's Disease. Neurology, 34, 939-944.

Moss, H. E., \& Tyler, L. K. (2000). A progressive category-specific semantic deficit for non-living things. Neuropsychologia, 38, 60-82.

Neary, D., Snowden, J. S., Gustafson, L., Passant, U., Stuss, D., Black, S., et al. (1998). Frontotemporal lobar degeneration: A consensus on clinical diagnostic criteria. Neurology, 51, $1546-1554$.

Price, C. J., Mummery, C. J., Moore, C. J., Frakowiak, R. S., \& Friston, K. J. (1999). Delineating necessary and sufficient neural systems with functional imaging studies of neuropsychological patients. Journal of Cognitive Neuroscience, 11, 371-382.

Pulvermuller, F. (1999). Words in the brain's language. Behavioral and Brain Sciences, 22, 253-279 [discussion 280-336]

Rizzolatti, G., Fogassi, L., \& Gallese, V. (2002). Motor and cognitive functions of the ventral premotor cortex. Current Opinion in Neurobiology, 12, 149-154.

Rogers, T. T., Lambon Ralph, M. A., Garrard, P., Bozeat, S., McClelland, J. L., Hodges, J. R., et al. (2004). Structure and deterioration of semantic memory: A neuropsychological and computational investigation. Psychological Review, 111, 205-235.

Rosazza, C., Imbornone, E., Zorzi, M., Farina, E., Chiavari, L., \& Cappa, S. (2003). The heterogeneity of category-specific semantic disorders: Evidence from a new case. Neurocase, 9, 189-202.

Sartori, G., \& Lombardi, L. (2004). Semantic relevance and semantic disorders. Journal of Cognitive Neuroscience, 16, 439-452.

Signorini, M., Paulesu, E., Friston, K., Perani, D., Colleluori, A., Lucignani, G., et al. (1999). Rapid assessment of regional cerebral metabolic abnormalities in single subjects with quantitative and nonquantitative [18F]FDG PET: A clinical validation of statistical parametric mapping. Neuroimage, 9 , 63-80.

Snodgrass, J. G., \& Vanderwart, M. (1980). A standardized set of 260 pictures: Norms for name agreement, image agreement, familiarity, and visual complexity. Journal of Experimental Psychology: Human Learning and Memory, 6, 174-215. 
Thompson-Schill, S. L., Aguirre, G. K., Desposito, M., \& Farah, M. J. (1999). A neural basis for category and modality specificity of semantic knowledge. Neuropsychologia, 37, 671-676.

Tippett, L. J., Glosser, G., \& Farah, M. J. (1996). A category-specific naming impairment after temporal lobectomy. Neuropsychologia, 34, 139-146.

Vermersch, P., David, J. P., Frigard, B., Fallet-Bianco, C., Wattez, A., Petit, H., et al. (1995). Cortical mapping of Alzheimer pathology in brains of aged non-demented subjects. Progress in Neuro-Psychopharmacology \& Biological Psychiatry, 19, 1035-1047.

Warrington, E. K., \& Shallice, T. (1984). Category specific semantic impairments. Brain, 107, 829-854.

Wise, R. J., Howard, D., Mummery, C. J., Fletcher, P., Leff, A., Buchel, C., et al. (2000). Noun imageability and the temporal lobes. Neuropsychologia, 38, 985-994.
Zahn, R., Buechert, M., Overmans, J., Talazko, J., Specht, K. Ko, C. W., et al. (2005). Mapping of temporal and parietal cortex in progressive nonfluent aphasia and Alzheimer's disease using chemical shift imaging, voxel-based morphometry and positron emission tomography. Psychiatry Research: Neuroimaging, 140, 115-131.

Zahn, R., Juengling, F. D., Bubrowski, P., Jost, E., Dykierek, P., Talazko, J., et al. (2004). Hemispheric asymmetries of hypometabolism associated with semantic memory impairment in Alzheimer's disease: A study using positron emission tomography with fluorodeoxyglucose-F18. Psychiatry Research Neuroimaging, 132, 159-172.

Zannino, G. D., Perri, R., Carlesimo, G. A., Pasqualetti, P., \& Caltagirone, C. (2002). Category-specific impairment in patients with Alzheimer's disease as a function of disease severity: A cross-sectional investigation. Neuropsychologia, $40,2268-2279$. 